\title{
ESOMEPRAZOLE-BASED SEQUENTIAL THERAPY AND PROBIOTIC FOR HELICOBACTER PYLORI ERADICATION
}

\author{
Miglena Stamboliyska, Iskren Kotsev \\ Clinic of Gastroenterology, St. Marina University Hospital of Varna
}

\begin{abstract}
PURPOSE: The objective of the present study was to determine the effectiveness of esomeprazole-based sequential therapy and Bio Gaya probiotic for the treatment of Helicobacter pylori-infection (Hp-infection) with associated gastroduodenal diseases.

MATERIAL AND METHODS: The study covered 104 patients with dominating upper dyspeptic syndrome and $\mathrm{Hp}$-infection examined by means of two or more methods. Esomeprazole-based sequential therapy consisted in amoxycillin in a dose of $1,0 \mathrm{~g}$ two times daily for the first five days followed by clarithromycin and metronidazole in a dose of $500 \mathrm{mg}$ two times daily for the next 5 days. A Bio Gaya probiotic was added during the 10-day treatment.

RESULTS: Hp-infection was successfully treated in 98 patients $(94,2 \%)$ and in 79 out of 81 naive ones $(97 \%$ of the cases). This therapy proved effective in 19 out of 23 patients $(82,6 \%)$ after one or two failed Hp-infection eradications, too. The treatment failed in 6 patients $(5,7 \%)$ because of a double antibiotic resistance.

CONCLUSION: The esomeprazole-based sequential therapy and Bio Gaya probiotic represented a highly and well-tolerable effective eradication option. Clinical symptoms and quality of life were favourable influenced in all the patients as well as side effects were rare.
\end{abstract}

Key words: Helicobacter pylori-infection, sequential therapy, esomeprazole, probiotic, eradication

\section{INTRODUCTION}

According to the Maastricht III Consensus Report (8), standard triple therapy (STT), double combination of clarithromycin and amoxicillin or metronidazole and proton pump inhibitor (PPI) for seven days are recommended and applied for Helicobacter pylori-infection (Hp-infection)

\footnotetext{
Address for correspondence:

Miglena Stamboliyska, MD

Clinic of Gastroenterology,

St. Marina University Hospital of Varna

1 Hristo Smirnenski Str., 9010 Varna, Bulgaria

e-mail:m.stamboliyska@abv.bg
}

Received: September 09, 2012

Accepted: March 04, 2013 eradication. Recent meta-analyses (7) show relatively low eradication rates following STT (less than $80 \%$ ). Hp antibiotic resistance mainly affects the effectiveness of eradication therapy (15) as eradication fails in $35-40 \%$ of the patients (15).

Sequential eradication therapy has been introduced 10 years ago in Italy and nowadays represents an innovative approach making use of well-known and approved drugs against Hpinfection. PPI exerts a direct antibacterial effect on Hp-infection (1) and creates favourable preconditions for the action of antibiotics thus being the basic component of eradication therapy. Secondgeneration PPI enables an optimal $\mathrm{pH}$ control of gastric acid secretion and higher eradication levels $(1,2)$. Elevation of omeprazole dosage of $20 \mathrm{mg}$ up to $40 \mathrm{mg}$ of esomeprazole twice daily increases the 
rate of healing of acid-associated diseases by $8-12 \%$ (17). Supplementation of a probiotic improves the effectiveness and tolerability of the eradication regimen (3).

The aim of this study was to determine the therapeutic effect of the esomeprazole-based sequential eradication regimen in combination with a probiotic in some gastroduodenal diseases associated with Hp-infection.

\section{MATERIAL AND METHODS}

The study covered 104 patients with dominating upper dyspeptic syndrome (Table 1). Most of them were examined and monitored concerning Hp-infection by means of two or more methods. Esomeprazole-based sequential therapy consisted in amoxycillin in a dose of $1,0 \mathrm{~g}$ twice daily for the first five days followed by clarithromycin and metronidazole in a dose of $500 \mathrm{mg}$ twice daily for the next 5 days. A Bio Gaya probiotic was added during the 10-day treatment. Esomeprazole was administered in a double dose of $40 \mathrm{mg}$ twice daily. A Lactobacilus reuteri (Bio Gaya) probiotic was added in a dose of $1,0 \mathrm{~g}$ twice daily for 10 days. Culture examination with antibiotic testing was performed in eight patients, i.e. before treatment in two and after failed therapy in six patients. Repeatedly endoscopy was done in the patients with peptic ulcer disease, usually, on the $40^{\text {th }}$ day after the initial examination as these with gastric ulcer were given esomeprazole in a dose of $40 \mathrm{mg}$ daily. All the patients filled in a questionnaire about their individual quality of life, drug tolerance and side effects.

\section{RESULTS}

Our results were systematized on Table 2.

Hp-infection was successfully treated in 98 patients $(94,2 \%)$ and in 79 out of 81 naive ones ( $97 \%$ of the cases). This therapy proved effective in 19 out of 23 patients $(82,6 \%)$ after one or two failed $\mathrm{Hp}$-infection eradications, too. The treatment failed in 6 patients $(5,7 \%)$ because of a double antibiotic resistance. Hp-infection was resistant to amoxicillin and clarithromycin in one patient and to clarithromycin and metronidazole in five patients. Hp-infection eradication was achieved in all the patients with peptic ulcer disease which correlated with ulcer epithelisation. Histomorphologically,
Table 1. Patients' demographic and clinical characteristics $(n=104)$

\begin{tabular}{ll} 
Parameters/Values (n/\%) & \\
mean age (years) & $54,5 \pm 15,7$ \\
gender (males/females) & $58(55,7) / 42(40,3)$ \\
smokers/non-smokers & $48(46,1) / 56(53,8)$ \\
patients' aged over 70 years & $21(20,1)$ \\
$\begin{array}{l}\text { examined dyspepsia } \\
\text { (proved by fibrogastroscopy) }\end{array}$ & $62(59,6)$ \\
repeated endoscopy & $23(22,1)$ \\
$\begin{array}{l}\text { peptic ulcer disease } \\
\text { (duodenal ulcer/gastric ulcer) }\end{array}$ & $22(21,1)$ \\
erosive antral gastritis & $23(22,1)$ \\
erythemic exudative gastritis & $5(4,8)$ \\
$\begin{array}{l}\text { exacerbated antral gastritis } \\
\text { atrophic gastritis }\end{array}$ & $7(6,7)$ \\
$\begin{array}{l}\text { non-ulcer dyspepsia } \\
\text { (not examined yet) }\end{array}$ & $5(4,8)$ \\
\hline
\end{tabular}

\section{Hp status}

histologic examination

$72(69,2)$

urease test

$85(81,7)$

fecal antigenic test

$72(69,2)$

fecal polymerase chain reaction

$15(14,4)$

urea breathing test

$31(29,8)$

culture examination

$8(7,6)$

naive patients

$81(77,8)$

after one or two failed

$23(22,1)$

eradications

there was a suppressed activity of gastritis and a restricted inflammatory infiltration. Eradication was achieved in 36 out of 42 patients (85\%) with nonulcer dyspepsia. The therapy was successful in all the patients aged over 70 years as well as in 46 smokers and 52 non-smokers. Clinical symptoms were favourably influenced in $100 \%$ of the cases. Only two patients with failed eradication did not report any improvement of their quality of life. All the patients except one tolerated well the sequential eradication 
Table 2. Therapeutic results

\begin{tabular}{lcc} 
Parameter & $\begin{array}{c}\text { Succesful eradication } \\
(\mathrm{n}=98)\end{array}$ & $\begin{array}{c}\text { Failed eradication } \\
(\mathrm{n}=6)\end{array}$ \\
mean age (years) & $55 / 39$ & $3 / 3$ \\
smokers/non-smokers & $46 / 52$ & $3 / 3$ \\
patients' aged over 70 years & 21 & - \\
non-ulcer dyspepsia & 36 & 6 \\
peptic ulcer disease & 22 & - \\
- duodenal ulcer with complete epithelization & 13 & - \\
- duodenal ulcer with incomplete epithelization & 3 & - \\
- gastric ulcer with complete epithelization & 5 & 6 \\
- gastric ulcer with incomplete epithelization & 1 & 2 \\
influenced clinical symptoms & 98 & 4 \\
naive patients & 79 & 2 \\
after one or two failed eradications & 19 & 5 \\
good quality of life & 98 & 1 \\
good tolerance & 98 & - \\
side effects & 5 & \\
\hline
\end{tabular}

therapy with a probiotic and presented with a good compliance. There were slight and rapidly transitory side effects in 6 patients only $(5,7 \%)$ consisting in bitter regurgitations in four patients, nausea and constipation in one patient each.

Two patients with failed eradication were naive and four ones had previously experienced one or two failed eradications. In all of them, the clinical symptoms were favourably influenced. Quality of life did not improve in two patients. A poor tolerance of the eradication regimen was shared by one patient. Only one patient complained of bitter regurgitations.

\section{DISCUSSION}

Our study confirms previous results about the higher effectiveness of sequential therapy in comparison with STT. Our eradication rate of $94,2 \%$ is similar to that of more than $98 \%$ reported in Italy (18). Our eradication rate in the naive patients is even of $97 \%$ that is similar to the results recently reported in Italy $(6,12,20)$. The sequential regimen proves much more effective than STT (14) even in the patients with failed previous one or two eradications with suspected or identified clarithromycin resistance. Although our patients presented with an initial clarithromycin resistance we have performed a successful Hp-infection eradication in them. The failure is due to the double antibiotic resistance. Probably, the very high effectiveness of our sequential regimen results from the properly selected PPI, i. e. of nexium (esomeprazole). According to the Maastricht IV/Florence Consensus Report (9) there is indirect and direct evidence of the possible enhancement of the eradication through the higher PPI dosage (16) as well as of the better effect of the double PPI dosage than the single one.

A meta-analysis demonstrates that $\mathrm{Hp}$ eradication rate depends on PPI presence that on its part depends on CYP2C19 and MDR polymorphisms (10). Esomeprazole (nexium), in contrast to omeprazole, an extensive metabolizing agent, represents a metabolizer of predominant polymorphism enabling a high eradication rate (10). Esomeprazole possesses an excellent pharmacological and pharmacodynamics characteristic as it achieves an optimal long-lasting acid $\mathrm{pH}$ control and ensures 
a better effect of antibiotics (13). Esomeprazole-based triple therapy is by $8 \%$ more effective than that with omeprazole although this difference is statistically insignificant $(1,2)$. Data about the necessary duration of the treatment with esomeprazole and other PPIs are contradictory $(1,4,13)$. The supplementation of Bio Gaya probiotic is of importance, too. Lactobacilus reuteri exerts a direct antibacterial effect on $\mathrm{Hp}$. It colonizes gastric mucosa and reduces bacterial loading (3) thus potentiating the eradication. It seems promising to treat $\mathrm{Hp}-$ infection with a probiotic combined with PPI thus eliminating the administration antibiotics and the antibiotic resistance as well. Probably, the probiotic influences on the tolerance to the eradication regimen and patient's quality of life during and after the eradication and leads to minimization of the side effects.

In contrast to our data, several studies report a higher frequency of side effects, between 10 and 17\% of the cases $(14,20,21)$. Diarrhoea occurs most often, however, it is absent in our contingent at all, even in the age group over 70 years. The rapid and complete improvement of the clinical symptoms is, most likely, due to the probiotic and high dose of esomeprazole. The risk factors which are predictors of STT failure (11) do not exert any effect on the results from the sequential and eradication treatment. The advantage of the combination of a sequential regimen and probiotic consists in the fact that it is independent of the risk factors for STT failure such as clarithromycin resistance, tobacco smoking and non-ulcer dyspepsia. In the senile patients with eradicated $\mathrm{Hp}$ infection, there is epithelisation of the gastric and duodenal peptic ulcer and gastritis suppression as well. Similarly to other authors $(5,19)$, we prove that this regimen should be recommended in patients with non-ulcer dyspepsia, too.

\section{CONCLUSION}

The esomeprazole (nexium)-based sequential regimen combined with Bio Gaya probiotic represents a highly and well-tolerable effective eradication option for the patients with $\mathrm{Hp}$-associated gastroduodenal diseases. It favourably influences on the clinical symptoms and patient's quality of life. Its side effects are slight and rare. This ideal regimen should be recommended for the clinical practice.

\section{REFERENCES}

1. Choi, H. S., D. I. Park, S. J. Hwang, J. S. Park, H. J. Kim, Y. K. Cho, et al. Double-dose, newgeneration proton pump inhibitors do not improve Helicobacter pylori eradication rate.- Helicobacter, 12, 2007, No 6, 638-642.

2. De los Ríos, R., J. L. Pinto, A. Zegarra, C. García, E. Refulio, A. Piscoya, et al. Esomeprazole-based triple therapy for the eradication of Helicobacter pylori in patients with non-ulcer dyspepsia.- Rev. Gastroenterol. Peru, 29, 2009, No 3, 234-238 (in Spanish).

3. Francavilla, R., E. Lionetti, S. P. Castellaneta, A. M. Magistà, G. Maurogiovanni, N. Bucci, et al. Inhibition of Helicobacter pylori infection in humans by Lactobacilus reuteri AT CC 55730 and effect on eradication therapy. A pilot study.Helicobacter, 13, 2008, No 2, 127-134.

4. Gisbert, J. P., A. Domínguez-Muñoz, A. Domínguez-Martín, J. L. Gisbert, S. Marcos. Esomeprazole-based therapy in Helicobacter pylori eradication: any effect by increasing the dose of esomeprasole or prolonging the treatment?- $\mathrm{Am}$. J. Gastroenterol., 100, 2005, No 9, 1935-1940.

5. Hassan, C., V. De Francesco, A. Zullo, G. Scaccianoce, D. Piglionica, E. Ierardi, et al. Sequential treatment for Helicobacter pylori eradication in duodenal ulcer patients: improving the cost of pharmacotherapy.- Aliment. Pharmacol. Ther., 18, 2003, No 6, 641-646.

6. Jafri, N. S., C. A. Hornung, C. W. Howden. Metaanalysis: sequential therapy appears superior to standard therapy for Helicobacter pylori infection in patients naive to treatment.- Ann. Intern. Med., 148, 2008, No 12, 923-931.

7. Laheij, R. J., L. G. Rossum, J. B. Jansen, H. Straatman, A. L. Verbeek. Evaluation of treatment regimens to cure Helicobacter pylori infection a meta-analysis.- Aliment. Pharmacol. Ther., 13, 1999, No 7, 857-864.

8. Malfertheiner, P., F. Megraud, C. O’Morain, F. Bazzoli, E. El-Omar, D. Graham, et al. Current concepts in the management of Helicobacter pylori infection: the Maastricht III Consensus Report.Gut, 56, 2007, No 6, 772-781.

9. Malfertheiner, P., F. Megraud, C. A. O’Morain, J. Atherton, A. T. Axon, F. Bazzoli, et al.; European Helicobacter Study Group. Management of Helicobacter pylori infection - the Maastricht IV/ 
Florence Consensus Report.- Gut, 61, 2012, No 5, 646-664.

10. Padol, S., Y. Yuan, M. Thabane, I. T. Padol, R. H. Hunt. The effect of CYP2C19 polymorphisms on $\mathrm{H}$. pylori eradication rate in dual and triple first-line PPI therapies: a meta-analysis.- Am. J. Gastroenterol., 101, 2006, No 7, 1467-1475.

11. Perri, F., M. R. Villani, V. Festa, M. Quitadamo, A. Andriulli. Predictors of failure of Helicobacter pylori eradication with the standard 'Maastricht triple therapy'.- Aliment. Pharmacol. Ther., 15, 2001, No 7, 1023-1029.

12. Sánchez-Delgado, J., X. Calvet, L. Bujanda, J. P. Gisbert, L. Titó, M. Castro. Ten-day sequential treatment for Helicobacter pylori eradication in clinical practice.- Am. J. Gastroenterol., 103, 2008, No 9, 2220-2223.

13. Scarpignato, $C$. Towards the ideal regimen for Helicobacter pylori eradication: the search continues.- Dig. Liver Dis., 36, 2004, No 4, 243-247.

14. Vaira, D., A. Zullo, N. Vakil, L. Gatta, C. Ricci, F. Perna, et al. Sequential therapy versus standard triple-drug therapy for Helicobacter pylori eradication: a randomized trial.- Ann. Intern. Med., 146, 2007, No 8, 556-563.

15. Vakil, N., F. Megraud. Eradication therapy for Helicobacter pylori.- Gastroenterology, 133, 2007, No 3, 985-1001.

16. Vallve, M., M. Vergara, J. P. Gisbert, X. Calvet. Single vs. double dose of a proton pump inhibitor in triple therapy for Helicobacter pylori eradication: a meta-analysis.- Aliment. Pharmacol. Ther., 16, 2002, No 6, 1149-1156.
17. Villoria, A. Acid-related diseases: are higher doses of proton pump inhibitors more effective in the treatment of Helicobacter pylori infection? Gastroenterol. Hepatol., 31, 2008, No 8, 546-547 (in Spanish).

18. Zullo, A., V. Rinaldi, S. Winn, P. Meddi, R. Lionetti, C. Hassan, et al. A new highly effective shortterm therapy schedule for Helicobacter pylori eradication.- Aliment. Pharmacol. Ther., 14, 2000, No 6, 715-718.

19. Zullo, A., L. Gatta, V. De Francesco, C. Hassan, C. Ricci, V. Bernabucci, et al. High rate of Helicobacter pylori eradication with sequential therapy in elderly patients with peptic ulcer: a prospective controlled study.- Aliment. Pharmacol. Ther., 21, 2005, No 12, 1419-1424.

20. Zullo, A., V. De Francesco, C. Hassan, S. Morini, $D$. Vaira. The sequential therapy regimen for Helicobacter pylori eradication: a pooled-data analysis.- Gut, 56, 2007, No 10, 1353-1357.

21. Zullo, A., V. De Francesco, C. Hassan, L. Ridola, A. Repici, V. Bruzzese, et al. Modified sequential therapy regimens for Helicobacter pylori eradication: a systematic review.- Dig. Liver Dis., 45, 2013, No 1, 18-22. 